\title{
ERRATUM
}

Toll-like receptor signalling in the intestinal epithelium: how bacterial recognition shapes intestinal function

\section{Maria T. Abreu}

Nature Reviews Immunology 10, 131-144 (2010); published online 25 January 2010; corrected after print 2 February 2010

In the version of the article initially published, figure 1 depicted Paneth cells at the base of the crypt in the colon. These cells should have been enterocytes. A corrected version is provided below. This has also been corrected in the HTML and PDF versions of this article.

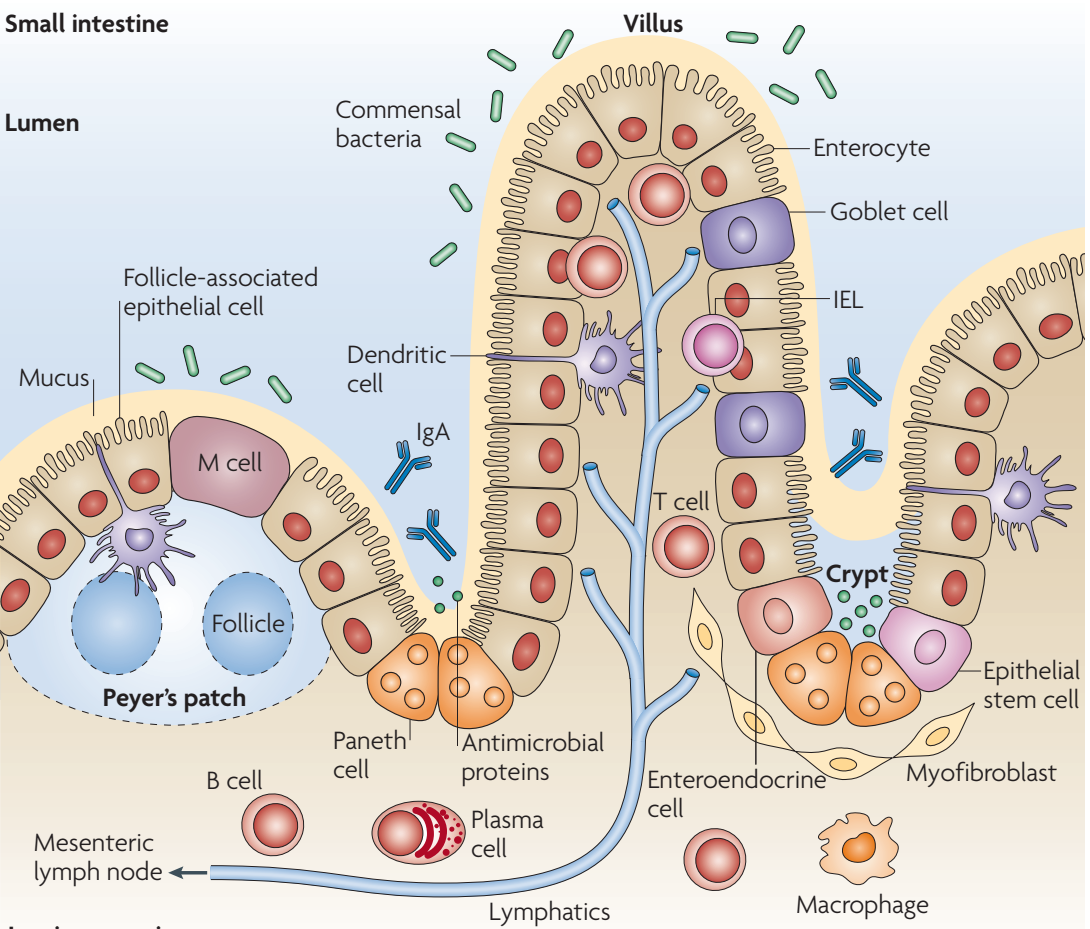

Lamina propria

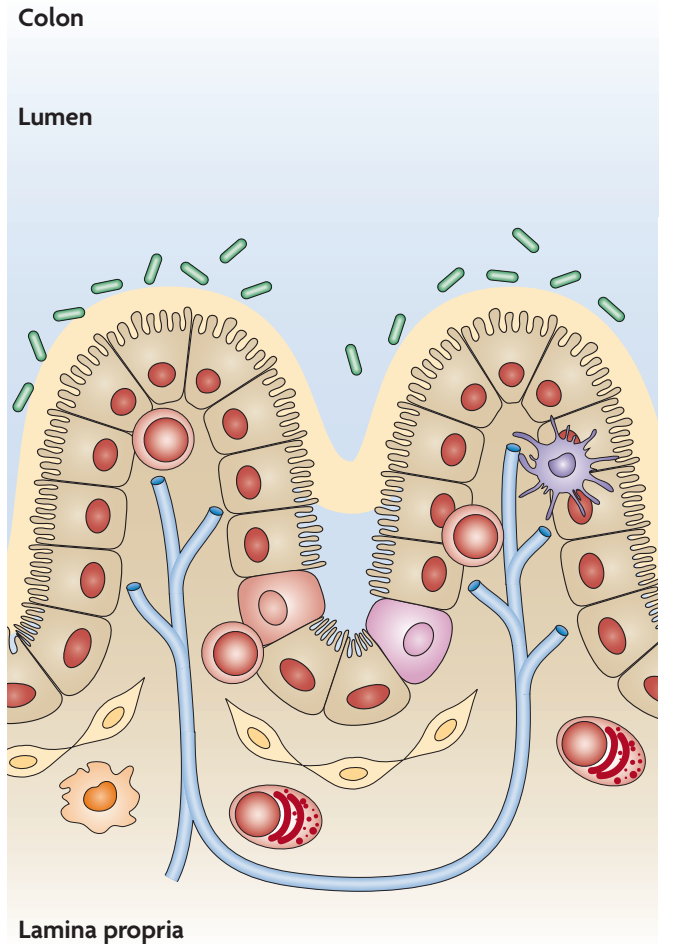

Figure 1 | Anatomy of the intestinal immune system. A single layer of intestinal epithelial cells (IECs) provides a physical barrier that separates the trillions of commensal bacteria in the intestinal lumen from the underlying lamina propria. The IECs lining the lumen are bathed in nutrients, commensal bacteria, IgA and goblet cell-produced mucus. Epithelial stem cells proliferate and give rise to daughter cells with the potential to proliferate. These IECs then differentiate into villous or colonic enterocytes, which absorb nutrients (small intestine) and water (colon). In addition to differentiated enterocytes and goblet cells, progenitor IECs differentiate into both enteroendocrine cells, which secrete enteric hormones, and Paneth cells at the base of the small intestinal crypts. Beneath the IECs, the lamina propria is made up of stromal cells (myofibroblasts), B cells (especially lgA-producing plasma cells), T cells, macrophages and dendritic cells. Certain subsets of T cells and dendritic cells localize between the IECs. The small intestine has regions of specialized epithelium termed follicle-associated epithelium and microfold $(M)$ cells that overlie the Peyer's patches and sample the intestinal lumen. IEL, intraepithelial lymphocyte. 